\title{
Language Environment Setting Through Our Foreign Currency Activities to Improve Chinese-Majoring Learners’ Competency
}

\author{
Dr. Mai Thi Ngoc Anh \\ Thai Nguyen University, Thai Nguyen Province, Vietnam
}

\begin{abstract}
Language education centers primarily on fostering linguistic skills and language communication skills for students. In the process of teaching Chinese language, it is in the classroom that is the place to foster student's linguistic competence and language communication capacity. Therefore, classroom teaching becomes the main place to foster the language ability and language communication capacity for students while the extracurricular activities are the place for students to apply the knowledge they have learned in the classroom in to the real world. Conducting a survey to investigate extracurricular activities for Chinese language majors at Thai Nguyen University, School of Foreign Languages, the paper proposes solutions to improve the effectiveness of extracurricular activities for students and create excitement for students in learning.
\end{abstract}

Keywords: setting language learning environment, efficiency, excitement, extracurricular activities, Chinese

\section{Overview of the Problem}

Kyriliuk Viktor (2011, p. 4) stated that extracurricular activities outside the classroom function mainly as coordinating with classroom teaching. In other words, teaching in class is mainly a place to receive knowledge and of a great effect in fostering language capacity of learners, while extracurricular activities mainly provide an environment for students to apply the acquired knowledge, which helps to foster students' language communication skills. Classroom teaching and extracurricular activities have with reciprocal relationships in that students can absorb language competencies from the classroom, while communication capacity is mainly acquired from extracurricular activities. Given Viktor’s light, Mi Zhe (2012, p. 15) illustrated the relation among classroom teaching, extra-curricular activities, linguistic competence and langustic-communicatuve capabilities in the following diagram:

Mai Thi Ngoc Anh, Ph.D., Dr., Department of Chinese, School of Foreign Languages, Thai Nguyen University, Thai Nguyen Province, Vietnam. 


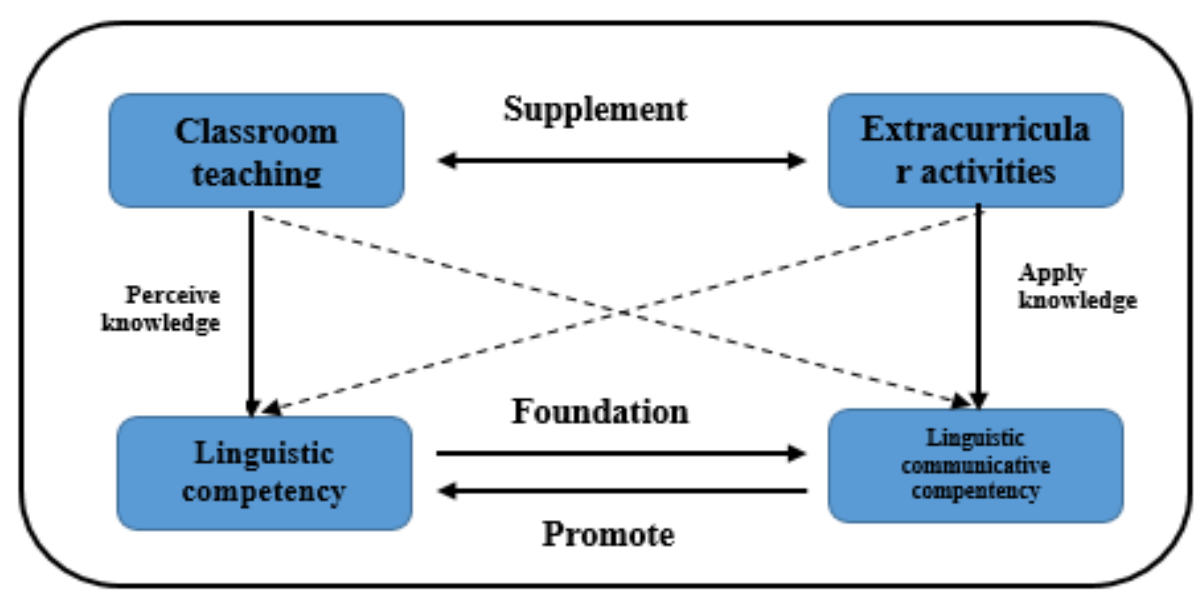

Figure 1. Model of the relationship between classroom teaching and extracurricular activities.

It can be seen that extracurricular activities happen outside the classroom to mainly supplement and support for class hours as a result of the needs of learning and teaching, under direct or indirect guidance of teachers. No matter what activities are, as long as they can attract students to participate, to expand, and to reinforce knowledge or students can be benefited from fostering knowledge, developing talent, excitement, and creativity, they are surely of certain values.

\section{The Meaning, Role, Characteristics and Structure of Extracurricular Activities}

\section{The Meaning of Extracurricular Activities}

Extracurricular activities and classroom teaching are a complete system, in which they mutually affect and make up for the other and both have important significance in teaching tasks and fulfill educational purposes. As an educational method, it has a great effect in the process of educational development.

Advantages of extracurricular activities are often taken by a large number of universities to supplement knowledge for class time learning, but what is questionable is how to use extracurricular activities efficiently. The simplest way is imagination, which can be named as design imagination. It is neither time- nor spacerestricted; teachers instruct students and try to develop students' creativity and imagination through logical thinking so that students can clearly see the actual situation and solve problems by which they are more motivated to study hard. Zhou P. (1999) said that "Imagination is by nature scientific as there are many scientific achievements derived from imagination” (as cited in Zhou \& Jiang, 1999, p. 48).

For this reason, it can be said that in the process of making ideas, imagination plays an important role. While knowledge is limited, imagination is infinite. In addition to reinforcing knowledge in class, extracurricular activities can also foster students' imagination and creativity. In extracurricular activities, students can work both manually and mentally, and develop problem-solving skills. In short, these activities can promote students' activity and foster positive thinking for students.

\section{The Role of Extracurricular Activities in Teaching}

Extracurricular activities help students learn and master the language. In the process of implementing activities, students can also supplement knowledge related to cultural language. Thus, extracurricular activities can play an important role in teaching. 
Class time for teaching is limited, but extracurricular activities are not limited in time, so teachers can base on the interest of students to implement activities, apply various types of methods, and reduce the monotonous binding of classroom lectures, so that learners can actively grasp knowledge. Extracurricular activities can increase students' interest and understanding of Chinese language and Chinese culture.

\section{Characteristics of Extracurricular Activities}

Viktor also argued that organizing extracurricular activities in the process of learning Chinese has long not merely been a concept of time and space. Its importance can be not only similar to that of classroom teaching but of significance regarding educational purposes, educational content, and educational methods and methods. Only by effectively applying these characteristics, extracurricular activities will be working for fostering students' language ability and language communication ability. Qiu said: "The nature of extracurricular activities lies in freedom and creativity” (Qiu, D. L, 2011, p. 23). In addition, it has the following characteristics:

1. With regard to the nature: It can be seen that extracurricular activities are outside the teaching plan, in which students voluntarily participate in and choose activities basing on their own preferences and strengths. Students can also make a choice on whether to participate in or not on the basis of their conditions and abilities.

2. With regard to the content: It can be seen that the scope, frequency, qualifications, and objects of these activities which are mainly built based on the students' level and interests are not limited.

3. With regard to formality: It can be seen that the duration, scale, number of participants, and locations of extracurricular activities are very flexible just as forms of extracurricular activities are various.

4. With regard to the method: It can be seen that extracurricular activities are conducted under the direction of teachers; they can enhance the independence and autonomy for students.

5. With regard to the stages: It can be seen that extracurricular activities can enhance the positivity and activeness of students in promoting practical language skills.

6. With regard to assessment: It can be seen that extracurricular activities can help students receive language in a comfortable and natural way.

7. With regard to educational significance: Extracurricular activities are not restricted by teaching plans, teachers can base on the needs of students to have appropriate design plans. Extracurricular activities can therefore be levelled and clearly purposive.

In short, extracurricular activities can provide students with a real language environment so that students can apply the acquired and perceived knowledge into the Chinese learning environment where the ultimate goal is to foster student's ability to self-study (Dong, 2010, p. 5).

\section{Basic Structure of Extracurricular Activity Model}

The must-be of extracurricular activities is to make true that activity, to strengthen old knowledge and to develop new knowledge to improve the level of Chinese for students. How clear activities are depends on how meticulous and careful instructors' guidance is. When designing extracurricular activities instructors need to design tasks that are similar to the content taught in class. The structure of the extracurricular activities model can be expressed as follows. 


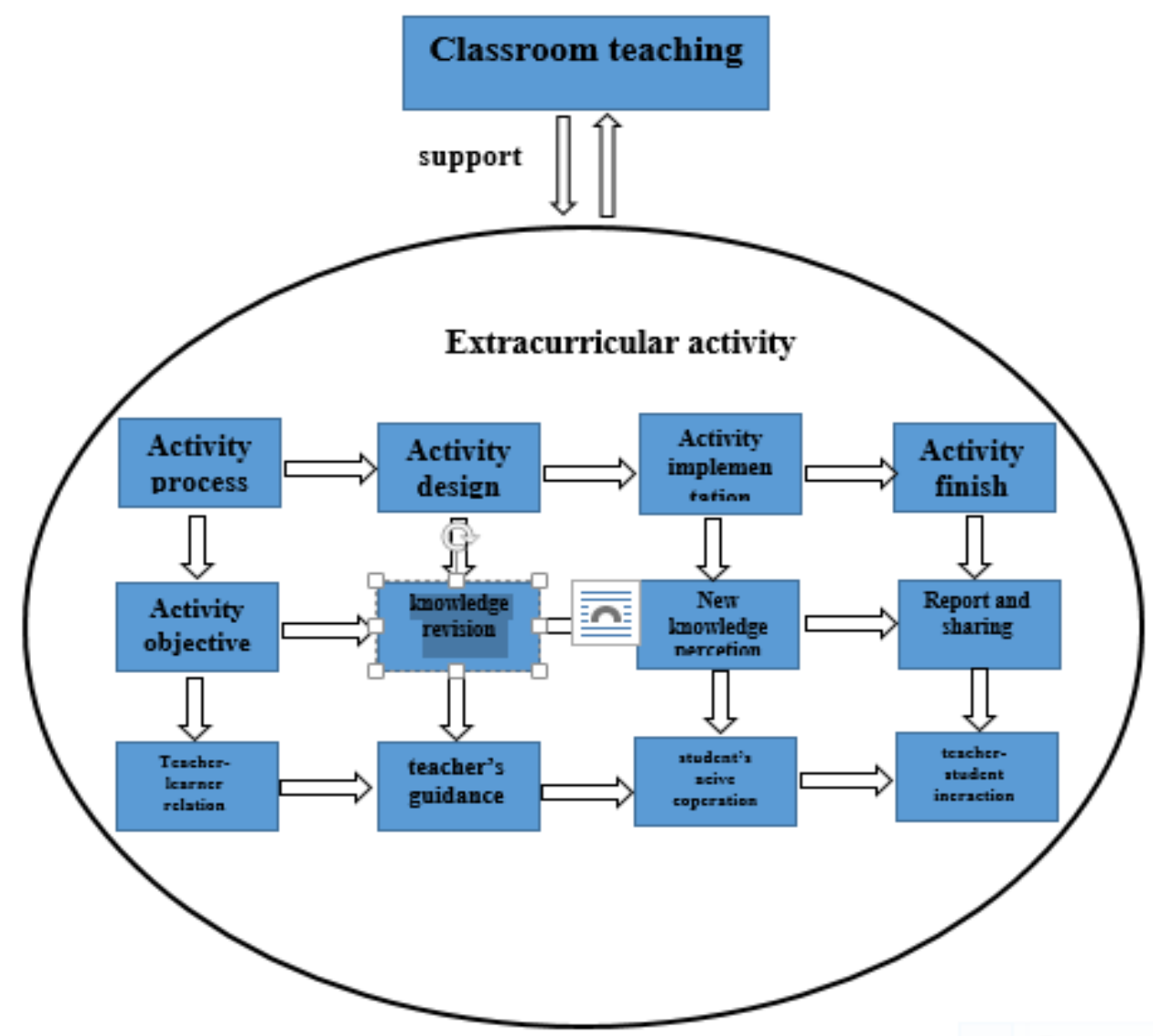

Figure 2. Extracurricular activity model.

From Figure 2, it can be seen that extracurricular activity is a model with a large circle whose all of its tasks derive from the knowledge learned in the class. Also, when all the extracurricular activities are deployed, all steps are intended to support student learning so that students can master the knowledge in the classroom. All steps in the model circulate but are interrelated and the final purpose is to help and supplement knowledge for learners.

\section{Current Extracurricular Activities at the Department of Chinese}

\section{Survey Process}

In order to understand the actual situation of extracurricular activities for students in Chinese language, at the Faculty of Foreign Languages, Thai Nguyen University, we conduct surveys for students through collecting opinions on extracurricular activities.

The content of the survey. It includes opinions on learners' interest in extracurricular activities; content of extracurricular activities learners have participated in; effect of participation in extracurricular activities; difficulties of extracurricular activities; and suggestions of learners about extracurricular activities.

Subjects of the survey. The survey subjects are 481 first-year to the fifth-year students, including Chinese Education, Chinese Language, Chinese-English Bilingual, and Chinese-Korean Bilingual Specializations. .

Survey method. Questionnaires were designed on Google forms and sent to teachers and students via different forms of social networks, like Facebook, Email, Messenger, and Zalo. The questionnaires were 
designed simple, easy to understand, with specific and clear content. The total of questionnaire sent to students of all grades and majors was 481 votes, and the collected totalled to 481 votes, reaching a ratio of $100 \%$.

\section{Survey Results and Causes of Effects}

Extracurricular activities do not meet the needs of students. When asked about their own interest in extracurricular activities related to Chinese, up to $60.2 \%$ of students think that they are interested in extracurricular activities; $35.1 \%$ of students are highly excited; and only $4.5 \%$ of students take no interest in extracurricular activities organized in the School.

When asked if students have ever participated in extracurricular activities, up to $17.8 \%$ of students sometimes joined, and $23.7 \%$ of students never participated in extracurricular activities held at Faculty

As shown by the survey findings, it is very important to improve the quality of extracurricular activities and select appropriate activities, according to the interests and needs of students. If they fail to meet the needs of learners, students will be gradually losing interests.

Extracurricular activities lack teacher's direction and enthusiastic guidance. The question is if there is any teacher's participation and if teachers are present, how does that involvement affect students. According to our observations during the experiment of extracurricular activities at the School of Foreign Languages, few teachers are involved with students, so teachers have not assisted greatly students and have not helped students use the knowledge they have learned to develop thinking and creativity in their activities.

Extracurricular activities do not have a clear goal. In the study results, up to $53 \%$ of students said that only a few activities required to use Chinese; $14.5 \%$ of students said that they were never asked to use Chinese; $24.8 \%$ said it was unclear whether the use of Chinese in activities was required; $53 \%$ said the activity was slightly effective for learning; and $42.2 \%$ said they worked to improve learners' Chinese ability. This shows that all activities that have been organized are very useful for students' learning of Chinese. However, the goal is not clear, so the activity is not really useful for students and do not support greatly for studying.

Extracurricular activities are sporadic and spontaneous. According to the survey, up to $42.3 \%$ of students hope that the activity should be organized once a month, $17.2 \%$ think it should be organized every two months, $12.8 \%$ desires an interval of three months; and $14.3 \%$ expect for it to be held once a week. This shows that students are eager to conduct extracurricular activities regularly and continuously, so teachers can base on the needs of students to divide themselves into groups, by size, yearly and periodically with specific plan and clear purpose and the full use of Chinese language. They also need expect what students will achieve. Only by such organization, can students be more motivated and excited.

Activities are insufficiently funded. When asked about the problem encountered in the process of participation, up to $37 \%$ said that there was no budget to buy materials to prepare for activities, so organized activities are not really effective due to the shortage of funding and granting.

\section{Recommendations and Suggestions}

On the base of the survey results, the paper proposes some of the following solutions to enhance students' interest in extracurricular activities.

Proposals and Suggestions in Selecting Topics, Identifying Objectives and Selecting Content for Extracurricular Activities

The theme of extracurricular activities must be appropriate. Extracurricular activities are not a 
learning program but they must also have a clear theme; choosing a good topic for the activity is enough to bring about success to the activity. Extracurricular activities are more flexible than mainstream teaching, so when choosing a topic must be necessarily match students' knowledge, attract students to actively participate in and teachers also should determine whether the content is feasible or limited by such factors as the level of the student, the environment or other restrictions. This is very important because if the topic is good but limited in some ways, it will be less likely to succeed.

Objectives of extracurricular activities must be specific. When thinking about the types of extracurricular activities, it is necessary to pay attention to the characteristics of extracurricular activities to determine the activity's objectives and formality. Besides, there must be a specific description of the goals for activities:

Content of extracurricular activities must be attractive. The selection of content of extracurricular activities is an important stage in activity design. First of all, to learn about extracurricular activities, it is necessary to take extracurricular activities as means to convey knowledge. When it comes to extracurricular activities, there are neither specific plans nor curricular like the classroom teaching curriculum. Instead, the content of the activity is based on the context, time, and the nature of the activity to be selected and then designed. The chosen content needs to promote students' thinking ability and based on the collected data, activities must be designed in a way that students reach more difficult knowledge than their current level. In doing so, students will gain a certain amount of knowledge. If interested in that knowledge, students will feel that learning is no longer stressful and can grasp knowledge quickly.

\section{Recommendations and Suggestions in How to Design Extracurricular Activities}

Need to close the topic. Extracurricular activities need to revolve around the to-be-implemented topic, so the content of the designed activity must be close to the topic; content and points of knowledge need to be related to topics. However, they are not necessarily only limited in the framework of the topic, but flexible in case of improvement preferred.

Need to be exploratory. In the process of designing activities, teachers need to stimulate students' interest and curiosity. Allow students to show their own autonomy to explore.

Need to be flexible. Extracurricular activity is a subject outside of the curriculum, so it requires flexibility. During the design process, teachers need to think carefully about whether there are any unlikely or problematic activities. In the event that there might be unplanned problems arising, teachers should be flexible instead of asking students to follow the planned activity. The design of extracurricular activities needs a smooth coordination of "discovery" and "extracurricular", not only ensuring not only the smoothness but also the flexibility for the activity.

Need to be cooperative. In the process of operation, students must work both individually and interactively to complete and acquire knowledge. So, learner players must have teamwork skills and interact with each other in order that the new activity is effective.

Need to be diversified. Extracurricular activities need to be diverse; the design needs to show the characteristics of activities; and materials also need to be diversified. Students can base on their own preferences and habits to choose activities. In the cooperation process, teachers and students also need to have the comfort, spatially and chronologically, to interact so that students have enough time and space to prepare and participate in activities. 
Need to take the knowledge, qualifications, and interests of students and society into consideration. When implementing extracurricular activities, the content of activities must be linked to the knowledge which is associated with designing extracurricular activities. The requirement for the design of every extracurricular activity related to different aspect of knowledge will be different. All kinds of knowledge must go through research and discovery to be achieved. Activities related to knowledge often have a great influence on the design of tasks. In addition, all activities need to pay attention to the factors related to students, including the current level, perceptions, and interests of each student.

\section{Proposals Proposed in the Organization and Implementation of Extracurricular Activities}

Raising students' awareness of extracurricular activities. In addition to ensuring the quality of class lectures, teachers must also take more care of students. In the process of teaching, teachers should introduce extracurricular activity models for students to comprehend. At the same time, teacher should clarify the effectiveness and benefits of extracurricular activities for learning so that students voluntarily participate instead of forcing them to do so. If forced, students will shortly lose their interest.

Teachers should focus on choosing the temporary activity topics. Extracurricular activities are not the same as teaching activities in the classroom in that teaching activities in the classroom need to be based on the curriculum, prepared lessons, but extracurricular activities are relatively flexible. By flexibility, teacher however must not arbitrarily choose the topic that must be kept relevant and conducive to performance. The topic must be related to life and social issues that are of great interest to the general public. If the topic is related to life, teachers can reduce the difficulty of implementing activities.

Contests for students' ideas on extracurricular activities should be organized. In order that extracurricular activities attract students and follow the students' wishes, teachers need to be flexible and creative. Teachers can take ideas from students themselves to organize activities. These ideas can be organized by teachers like a competition, with topics, such as "student's creativity contest". Such creative ideas by students themselves will attract many students because only students understand what they need and want to improve themselves. Besides, students also feel the initiative useful for the general activities of students in the School.

\section{Recommendations and Suggestions in Applying Viktor's Network Communication Model to Extracurricular Activities}

Viktor's extracurricular activity model is divided into five categories: extracurricular activities that support classroom teaching; network communication activities; practical activities with everyday topics; extracurricular activities with topics of sports and culture; and activities on social investigation, interview, sightseeing, and travel. Applying Viktor's network communication model, we designed the website to support learning for Chinese-majoring students to improve the Chinese language skills for students.

\section{Requirements for the system.}

1. The system works on the Internet (web-based) and allows many users to access and use at the same time.

2. The system meets safety and security capabilities according to two levels: user authentication level and Database level.

3. All data need to be managed, must be stored in the encrypted database with strict accessibly assignment.

4. Access speed is ensured at the appropriate level. 


\section{Target users of the system.}

\section{Guest:}

1. Be the object who access the website to learn about information, content of learning and other scientific resources.

2. Be any object without an account on the system.

3. Have the right to search for information.

4. Has the right to register as a user (User).

5. Interact exchangably through comments below the directory.

\section{User:}

1. Are guests who have already had an account and can log into the system.

2. Have the right to manage their personal accounts, change personal information, and see the progress of the courses being studied.

3. Can start any new course, or continue their courses.

4. Open the comment feature.

\section{Administrator:}

1. After logging into the system, the administrator has the right to:

2. Manage comments, feedback questions and users' feedback through specific messages or specific comments in some articles.

3. Manage and share academic resources.

\section{Architectural design of the system.}

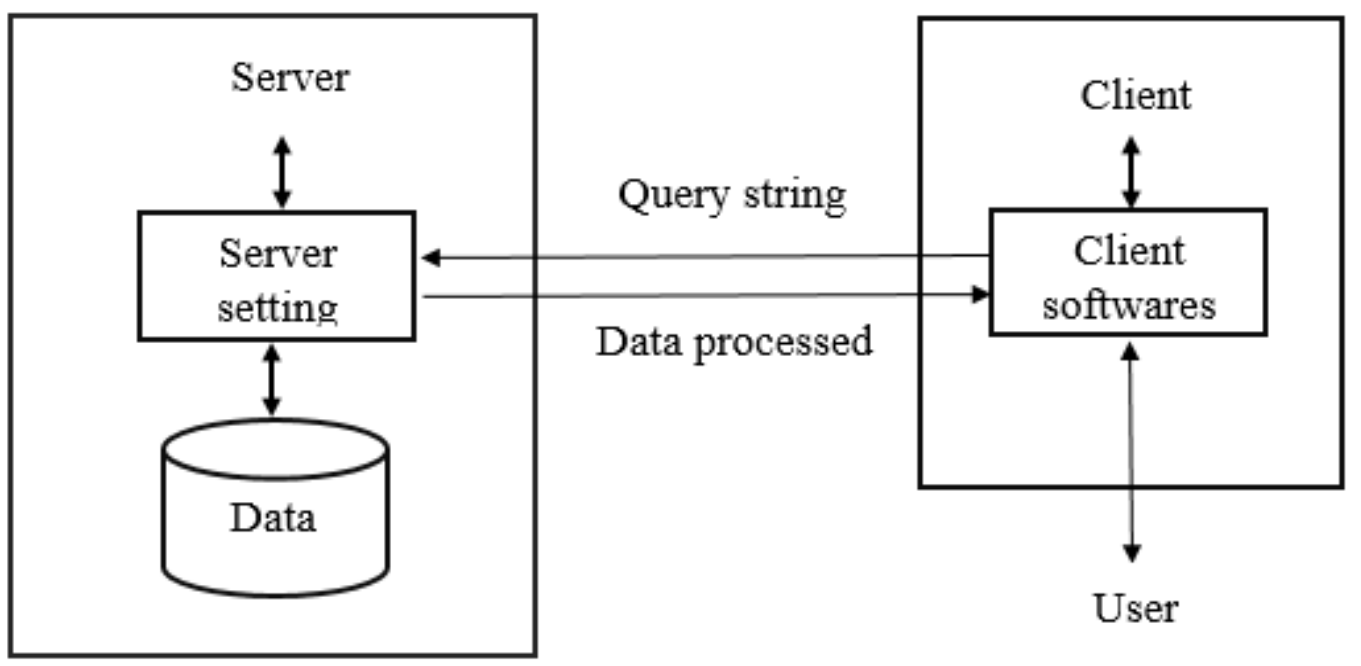

Figure 3. Client-server model.

The client-server model is a well-known model in computer networks, which is widely applied and is a model of every existing website. Each software built under the client-server model will be divided into two parts: The part operating on the server is called the Server side and the part operating on the workstation is called the Client side. With this model, workstations are also called clients (or client machines) and servers are called servers. The duties of each section are defined as follows: 
1. The Server side manages the external environment communications at the Server and with the Client, receives requests in the form of strings (query string), analyzes query strings, processes data, and sends the results reply to the Client.

2. The Client side organizes communication with the user, with the external environment at the workstation and on the Server side; receives the user's request; establishes query strings to the Server, and receives results and performs them.

\section{Website's utility.}

1. Can be used for free.

2. Is a rich and diverse resource.

3. Can interact with exchange of language resources.

4. There are two languages: Chinese and Vietnamese, so it is easy to understand and self-study.

5. Save time for searching related knowledge

6. Have images, audio, video, story suitable for content and easy to see and understand...

7. Include many appropriate types of reading comprehension and writing practice of Chinese characters, vocabulary, and grammar to each level.

8. Have Chinese Proficiency Test (HSK) tests for all levels.

Operation of the website. The website system is built on the principle that aesthetics and the content entirety related to learning and teaching Chinese are ensured, user-friendly and there is no need to register for access to the website. It can be used anywhere and on any browser. This process is set up according to the following steps:

Step 1: Determine the goals and the urgency of setting up the website. Firstly, survey on Chinese learning environment at Faculty of Foreign Languages, Thai Nguyen University, was conducted. The survey found that most students thought that the Internet was very important for learning Chinese, thereby serving as a basis for building learning content for the system.

Step 2: Determine the structure and content of the website. This is an important step to build on the website whose structure is divided into 8 sections including 6 main sections. Detailed content covers the entire knowledge in Chinese from the basic level to advanced one; the content is systematized, simplified, and easy to understand, of practicality, and helps learners review the knowledge that they have not yet firmly grasped.

Step 3: Select students to make websites. All the content on the website is done by the students of Chinese language, so the selection of students to participate to design the website is also very important. They are selected from Chinese classes in the Department and mainly divided into two groups:

Group 1: In charge of compiling, translating information, and collecting information for posting on the website.

Group 2: In charge of recording as broadcasters to read current news and student life's affairs, as well as activities related to the Department of Chinese.

Step 4: Collect information and content. After recruiting students to make websites, the web team will base on the website's categories to divide the workload. The content will be collected from students studying in the Faculty.

Step 5: Conduct compilation and put information on the website. After collecting information, the website team will compile the collected contents. After the compilation is completed, the team edits and puts the content on the website according to each item. 
Step 6: Continuously add content. Content will be continuously updated and supplemented to increase the novelty and attractiveness to users.

The content of extracurricular activities is web-based (Website address: hoctienghanknn.com). The website includes many contents such as Chinese language tests, Chinese knowledge, Chinese culture, learning resources, student's activities, and scientific research information. Designed extracurricular activities are included in these sections and they are organized as follows:

Role-play daily communication situations. Students can apply the knowledge they have learned in class and design short conversations in daily life, teachers edit content and grammar. Then, upon the editing, they record the conversations and video conversations will be posted on the website. Students through engaging in situations can improve their writing capacity and oral abilities.

Monthly news editing. A news editor group is established during the month; newsletters will be edited by students based on the content of School's monthly news and activities. Through editing the news, students improve their writing ability, summarizing skills, gathering information and expression, and support students in the editorial activities as journalists later.

Story translation. Students choose short stories and translate them from Vietnamese into Chinese. Through storytelling, students can improve their translation ability and help other students have the opportunity to participate Chinese-Vietnamese translation.

Making news of the monthly news. Organizing students to record news and news articles every month; students gather all monthly news for the School, and translate them into Chinese, the whole internal editing content and images as well as videos of the activity will be gathered and students in the group will be responsible for reading news and video recordings as news videos. Through this activity, students can improve their ability to translate, written and oral proficiency, reading comprehension and use teamwork skills and presenting in front of cameras, and be more confident in life. This activity can be supportive for the subject "Chinese TV Project", helping students become more confident in the next lesson.

Organize writing competitions and choose good essays from writing classes. writing contests are regularly organized and good essays are selected from best students of writing classes to post on the website. Students can therefore practice their own writing skills; good essays will be posted on the website as references for Chinese language majors in the School.

Organizing extracurricular activities through tourism projects, television projects and other activities. Subjects of tourism project and television project and other activities of students will be uploaded to the website, in which students can participate in tourism projects, recommend certain tourist destinations or participate in a television report on a certain issue. All of the above content will be posted on the website as a reference for students to study.

The website includes a lot of useful content covering not only important information, such as Chinese characters, vocabulary, and Chinese grammar, but also an environment to organize many interesting, useful, and reasonable extracurricular activities for students after school who would become more interested and confident in the subject.

\section{Conclusion}

In order to reinforce and improve the Chinese language ability for students, teachers can not only teach in the classroom but also need to establish a learning environment for students in many ways, in which setting up 
the environment through extracurricular activities is crucial. Such establishment not only helps learners reinforce the knowledge and skills they have learned in class but also contributes to promoting creativity and thinking ability of learners in practical activities. Learners will stay more confident, creative and can promote their own abilities so that they can use the knowledge they have learned in life, in the future and are more qualified.

\section{References}

Dong, L. (2010). English Extracurricular Activities: Learner’s Active Construction. Foreign primary and Secondary Education, p. 5 .

Qiu, D. L. (2011). Recognition of the Conceptual Category and Functional Value of Comprehensive Practical Activity Course and Extracurricular Activity, Theory \& Practice of Education, p. 23.

Viktor, K. (2011). Types and Design of Extracurricular Activities in Teaching Chinese. Hebei: Hebei Normal University, p. 4.

Zhe, M. (2012). Task-based on the Indonesian Chinese Extracurricular Activities Design. Shandong: Shandong Normal University, p. 15.

Zhou, P., \& Jiang, H. (1999). Complementary Advantages of Teaching Activities Inside and Outside the Classroom. Beijing: Foreign Language and Foreign Language Teaching, p. 48. 